\title{
The impact of free convection on late morning ozone decreases on an Alpine foreland mountain summit
}

\author{
J.-C. Mayer ${ }^{1}$, K. Staudt ${ }^{2}$, S. Gilge ${ }^{3}$, F. X. Meixner ${ }^{1,4}$, and T. Foken ${ }^{2}$ \\ ${ }^{1}$ Biogeochemistry Department, Max Planck Institute for Chemistry, Mainz, Germany \\ ${ }^{2}$ Department of Micrometeorology, University of Bayreuth, Bayreuth, Germany \\ ${ }^{3}$ German Meteorological Service, Observatory Hohenpeißenberg, Hohenpeißenberg, Germany \\ ${ }^{4}$ Department of Physics, University of Zimbabwe, Harare, Zimbabwe
}

Received: 8 January 2008 - Published in Atmos. Chem. Phys. Discuss.: 17 March 2008

Revised: 19 August 2008 - Accepted: 1 September 2008 - Published: 15 October 2008

\begin{abstract}
Exceptional patterns in the diurnal course of ozone mixing ratio at a mountain top site (998 $\mathrm{m}$ a.s.1.) were observed during a field experiment (September 2005). They manifested themselves as strong and sudden decreases of ozone mixing ratio with a subsequent return to previous levels. The evaluation of corresponding long-term time series (2000-2005) revealed that such events occur mainly during summer, and affect the mountain top site on about $18 \%$ of the summer days. Combining (a) surface layer measurements at mountain summit and at the foot of the mountain, (b) in-situ (tethered balloon) and remote sensing (SODAR-RASS) measurements within the atmospheric boundary layer, the origin of these events of sudden ozone decrease could be attributed to free convection. The free convection was triggered by a rather frequently occurring wind speed minimum around the location of the mountain.
\end{abstract}

\section{Introduction}

A sudden drop of the mean mixing ratio of any trace gas species down to around $20 \%$ of its initial value is, without doubt, noticeable. If this happens at a place and time of the day, where it is not expected from present knowledge, it is worth to be studied more thoroughly. Furthermore, if such events occur frequently, it warrants further study, particularly for measurements being made at comparable sites. Because a high frequency of occurrence may affect the statistical description of the mean temporal behaviour, these events should be well understood.

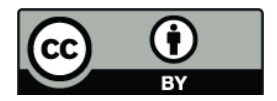

Correspondence to: J.-C. Mayer (jcmayer@mpch-mainz.mpg.de)
The mean diurnal cycle (i.e. the expected course) of ozone $\left(\mathrm{O}_{3}\right)$ mixing ratio in the surface layer and at higher altitudes of the atmospheric boundary layer (ABL) is primarily dependent on the photostationary state. Within the surface layer, $\mathrm{O}_{3}$ is depleted during night time due to deposition processes and reaction with nitric oxide (NO). During daytime, this process is overcompensated by photolysis of nitrogen dioxide $\left(\mathrm{NO}_{2}\right)$ followed by $\mathrm{O}_{3}$ production and transport of $\mathrm{O}_{3}$ (Aneja et al., 2000). These changes are less and less pronounced towards higher altitudes and finally become unimportant when reaching altitudes above nocturnal inversions, where $\mathrm{O}_{3}$ mixing ratio is expected to maintain its level from the preceding day during the night (residual layer) (Aneja et al., 2000; Fast et al., 2000). However, the diurnal cycle of $\mathrm{O}_{3}$ mixing ratio is subject to a variety of influences, from which some may still be unknown. They manifest themselves in sudden changes of mixing ratio on different time scales, ranging from minutes to days.

In general, changing $\mathrm{O}_{3}$ levels are frequently observed and reported. Some reports address the expected diurnal cycle of $\mathrm{O}_{3}$, either from ground based data (Wanner et al., 1993; Lin et al., 2004; Rummel, 2005) or from profile data (Güsten et al., 1998; Cheng, 2000). On the other hand, several studies report deviations from the "typical" behaviour. Possible reasons were found to be (a) large scale processes like frontal passages (Müller and Sladkovic, 1990), (b) changes of air masses (Strong et al., 2002), (c) mesoscale circulations like sea breezes (Hastie et al., 1999), and (d) mountain-valley circulations (Prévôt et al., 2000). Nocturnal low-level jets (LLJ) frequently cause secondary $\mathrm{O}_{3}$ maxima during night time (Corsmeier et al., 1997; Reitebuch et al., 2000; Lee et al., 2003; Salmond and McKendry, 2002), while advection of polluted air masses has been observed as a pronounced

Published by Copernicus Publications on behalf of the European Geosciences Union. 


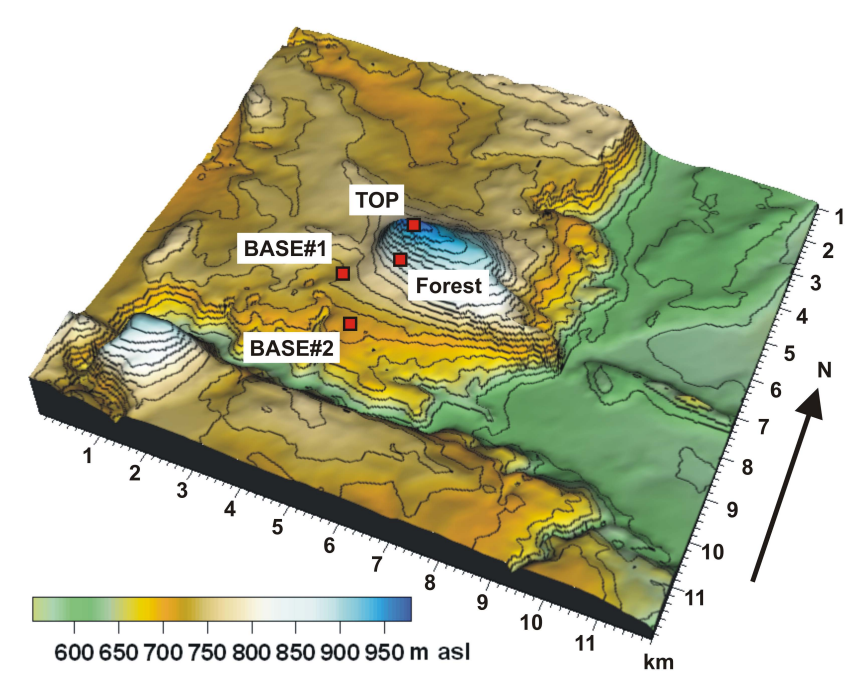

Fig. 1. Contour map of the SALSA site. Red dots indicate locations of the meteorological observatory at top of the mountain (TOP station, $998 \mathrm{~m}$ a.s.1.), of the forest station ( $850 \mathrm{~m}$ a.s.1.) and of the two field stations at the foot of the mountain, stations BASE\#1 (flux station, $735 \mathrm{~m}$ a.s.1.) and BASE\#2 (sounding station, $710 \mathrm{~m}$ a.s.1.).

layering in $\mathrm{O}_{3}$ profiles in the ABL (McKendry et al., 1997; Güsten et al., 1998; Beyrich et al., 1996; McKendry et al., 1998). There are only a few reports on exceptional patterns in diurnal $\mathrm{O}_{3}$ courses at mountain tops, and the observed deviations were always towards higher than the expected $\mathrm{O}_{3}$ mixing ratios (Attmannspacher and Hartmannsgruber, 1973; Yelansky and Senik, 1995). However, an explanation for short time decreases of $\mathrm{O}_{3}$ ( 0.5 to $2 \mathrm{~h}$ ) at a mountain top was not given in any of the mentioned reports. Therefore, a comprehensive set of noticeable observations at a mountain top, at the foot of the mountain and from profiles within the ABL will be used in this study to explain the origin of such short time events.

\section{Material and methods}

\subsection{The SALSA site}

Our measurements were conducted during the SALSA2005 campaign (22 August 2005-23 September 2005) which took place at and around the Hohenpeissenberg (German spelling: Hohenpeißenberg), an isolated mountain $\left(47^{\circ} 48^{\prime} \mathrm{N}\right.$, $11^{\circ} 02^{\prime} \mathrm{E}, 998 \mathrm{~m}$ a.s.l.) in Bavaria, southern Germany. The mountain Hohenpeissenberg is located approximately $70 \mathrm{~km}$ southwest of the city of Munich and $40 \mathrm{~km}$ north of the northern ridge of the Alps. It is covered by coniferous and mixed forest with some clearings and agriculturally used areas (managed pastures). The mountain summit is approx. $300 \mathrm{~m}$ higher than the surrounding area (Fig. 1). In the east of the mountain, the terrain slopes abruptly to a considerably lower level (approx. $600 \mathrm{~m}$ a.s.l.), while in the south the
Ammer river cuts into the terrain, forming a deep canyon. SALSA is a German acronym, which stands for "Contribution of nitrous acid to atmospheric $\mathrm{OH}$ concentration".

\subsection{The SALSA set-up}

The set-up of the field experiment was designed to account for (a) the complex terrain, (b) the expected main regime of wind flow and (c) the existing infrastructure, i.e. the Hohenpeissenberg observatory of the German Meteorological Service (DWD), situated on top of the mountain, later referred to as the "TOP" station. All parameters measured at TOP station, being relevant for this paper, are listed in Table 1.

In addition to the TOP station, two field stations were set up. At the south-western foot of the mountain, on a managed pasture site (approx. $1.1 \mathrm{~km}$ from TOP, see Fig. 1), eddy covariance systems for the measurement of sensible and latent heat fluxes were set up (BASE\#1, see Table 1). The second field station was installed to monitor the state of the $\mathrm{ABL}$ with respect to wind velocity, turbulence intensity and thermal stratification. This site (BASE\#2, see Table 1) was located directly south of the mountain (approx. $1.6 \mathrm{~km}$ from TOP, and approx. $1 \mathrm{~km}$ southeast of BASE\#1), on a plateau between the mountain and the Ammer river (see Fig. 1). Two sounding systems were deployed here: (1) a SODAR-RASS system (DSDPA90.64, METEK, with 1.29 GHz RASS extension), providing vertical profiles (20 m resolution) of wind velocity, fluctuation of the vertical wind speed and acoustic temperature, and (2) a tethered balloon system (Vaisala TMT, Boulder, CO, USA), which was used for discontinuous profiling of the $\mathrm{ABL}$ for air temperature, relative humidity, as well as mixing ratios of $\mathrm{CO}_{2}$ and $\mathrm{O}_{3}$. The meteorological sensor package of the tethered balloon system consisted of a thermistor for air temperature, a polymer based sensor for relative humidity, and a semiconductor technique based transducer for barometric pressure measurements. Wind speed $\left(\mathrm{v}_{h}\right)$ was measured by a 3-cup anemometer, and wind direction $(\phi)$ was determined by a vane referring to an electronic compass. The $\mathrm{CO}_{2}$ sonde was constructed around the GMP343 sensor (Carbocap, Vaisala), which uses a singlebeam dual-wavelength NDIR technology. Data were stored in a small data logger every $2 \mathrm{~s}$. The lightweight $\mathrm{O}_{3}$ sonde, a development of the University New Hampshire, is based on single beam UV absorption (Talbot et al., 2006). Its data were internally stored to a memory and downloaded after the flight. Flights with the tethered balloon were performed only in the evening and morning hours. Around noon, turbulence became too strong for safe and undisturbed measurements. Furthermore, for security reasons, the flights were generally limited to conditions of wind speeds less than $9 \mathrm{~m} \mathrm{~s}^{-1}$. The trace gas sondes were attached directly below the belly of the blimp-shaped balloon to avoid swinging payload. Three meteorological probes, each measuring wind speed and wind direction, air temperature, relative humidity and barometric pressure, were attached to the tether line with $5 \mathrm{~m}$ vertical 
Table 1. Measured parameters at the TOP station, forest station and the two sites of the BASE.

\begin{tabular}{|c|c|c|c|c|c|}
\hline Parameter & Symbol & Unit & Temporal resolution (min) & Sampling height (m) a.g.l. & Instrument (Model) \\
\hline \multicolumn{6}{|c|}{ TOP station, $998 \mathrm{~m}$ above sea level } \\
\hline Air temperature & $\mathrm{T}$ & ${ }^{\circ} \mathrm{C}$ & 1 & 2 & PT100 \\
\hline Relative Humidity & $\mathrm{rH}$ & $\%$ & 1 & 2 & LiCl-Sensor, Rotronic \\
\hline Air pressure & $\mathrm{P}$ & $\mathrm{hPa}$ & 1 & 2 & \\
\hline Horizontal wind speed & $\mathrm{v}_{h}$ & $\mathrm{~ms}^{-1}$ & 1 & 40.5 & Cup anemometer, heated \\
\hline Wind direction & $\phi$ & $\circ$ & 1 & 40.5 & Vane, heated \\
\hline Global radiation & $\mathrm{R}_{g}$ & $\mathrm{Wm}^{-2}$ & 1 & 18 & CM11, Kipp \& Zonen \\
\hline Ozone & $\mathrm{O}_{3}$ & $\mathrm{ppb}$ & 1 & 18 & UV absorption; ThermoElectron, 49C \\
\hline Nitric oxide & NO & $\mathrm{ppb}$ & 1 & 18 & Chemiluminescence; ECO Physics CLD 770 AL ppt \\
\hline Nitrogen dioxide & $\mathrm{NO}_{2}$ & $\mathrm{ppb}$ & 1 & 18 & ECO Physics CLD 770 AL ppt with PLC 760 \\
\hline Carbon monoxide & $\mathrm{CO}$ & $\mathrm{ppb}$ & 1 & 18 & Resonance fluorescence; Aero Laser AL 5001 \\
\hline \multicolumn{6}{|c|}{ BASE\#1 station, $735 \mathrm{~m}$ above sea level, flux site } \\
\hline Sensible heat flux & $\mathrm{H}$ & $\mathrm{Wm}^{-2}$ & 30 & 2 & Campbell CSAT3 \\
\hline Friction velocity & $u_{*}$ & $\mathrm{~ms}^{-1}$ & 30 & 2 & Campbell CSAT3 \\
\hline \multicolumn{6}{|c|}{ BASE\#2 station, $710 \mathrm{~m}$ above sea level, sounding site } \\
\hline Air temperature & $\mathrm{T}$ & ${ }^{\circ} \mathrm{C}$ & 5 & 2 & Rotronic \\
\hline Relative humidity & $\mathrm{rH}$ & $\%$ & 5 & 2 & Rotronic \\
\hline Air pressure & $\mathrm{P}$ & $\mathrm{hPa}$ & 5 & 1 & Vaisala, PTB101B \\
\hline Horizontal wind speed & $\mathrm{v}_{h}$ & $\mathrm{~ms}^{-1}$ & 5 & 2 & Vector instruments \\
\hline Wind direction & $\phi$ & $\circ$ & 5 & 2 & Vector instruments \\
\hline Ozone & $\mathrm{O}_{3}$ & $\mathrm{ppb}$ & 5 & 3.5 & ThermoElectron, 49C \\
\hline Nitric oxide & NO & $\mathrm{ppb}$ & 5 & 3.5 & TECAN $700 \mathrm{AL}$ \\
\hline Nitrogen dioxide & $\mathrm{NO}_{2}$ & $\mathrm{ppb}$ & 5 & 3.5 & TECAN $700 \mathrm{AL}$ \\
\hline Carbon dioxide & $\mathrm{CO}_{2}$ & ppm & 5 & 3.5 & LiCor 840 \\
\hline Water vapour & $\mathrm{H}_{2} \mathrm{O}$ & ppth & 5 & 3.5 & LiCor 840 \\
\hline Acoustic temperature & $\mathrm{T}_{a}$ & ${ }^{\circ} \mathrm{C}$ & 5 & $40-450$ & RASS, METEK \\
\hline Horizontal wind speed & $\mathrm{v}_{h}$ & $\mathrm{~ms}^{-1}$ & 5 & $40-450$ & SODAR, METEK \\
\hline Wind direction & $\phi$ & $\circ$ & 5 & $40-450$ & SODAR, METEK \\
\hline Reflectivity & $\mathrm{R}$ & $\mathrm{dB}$ & 5 & $40-450$ & SODAR, METEK \\
\hline Air temperature & $\mathrm{T}$ & ${ }^{\circ} \mathrm{C}$ & Approx. 30 & $1-450$ & Tethered balloon, TMT, Vaisala \\
\hline Relative humidity & $\mathrm{rH}$ & $\%$ & Approx. 30 & $1-450$ & Tethered balloon, TMT, Vaisala \\
\hline Air pressure & $\mathrm{P}$ & $\mathrm{hPa}$ & Approx. 30 & $1-450$ & Tethered balloon, TMT, Vaisala \\
\hline \multicolumn{6}{|c|}{ Forest station, $850 \mathrm{~m}$ above sea level } \\
\hline Horizontal wind speed & $\mathrm{v}_{h}$ & $\mathrm{~ms}^{-1}$ & 5 & 2 & Vector instruments \\
\hline Wind direction & $\phi$ & $\circ$ & 5 & 2 & Vector instruments \\
\hline
\end{tabular}

spacing between each other. The uppermost probe was located approximately $5 \mathrm{~m}$ below the balloon.

An additional forest station was located directly down slope (south flank) of the TOP station, halfway to the village of Hohenpeissenberg. Its data of wind speed and wind direction were used to check if air masses could have been transported very close to the ground toward the TOP station.

All measured parameters are listed in Table 1. For practical reasons, both field sites at the foot of the mountain (BASE\#1 and BASE\#2) will be considered as the "BASE" (in contrast to TOP station).

\subsection{Quality control}

Data from all ground based measurements were checked for periods with erroneous data due to power failures and subsequent restarting procedures as well as for artificial trace gas peaks originating from farming and other agricultural man- agement activities close by. Flux data were prepared for analysis by applying an established quality control scheme (Foken et al., 2004).

Profile data obtained by the SODAR-RASS system were quality controlled by using an internal quality code, provided by the SODAR-RASS system (METEK User handbook of SODAR/RASS, 2000). Subsequently, a despiking procedure was applied, based on the procedure published elsewhere (Vickers and Mahrt, 1997).

All deployed meteorological sondes were compared against the current data of the ground based system before flight (i.e. typically in the early morning and late afternoon). These parameters were: air temperature, relative humidity and barometric pressure. Tethersonde flight data were quality controlled by cross checking all parameters, measured independently by the three meteorological sondes, for consistency. The altitude of the sonde was recalculated after each flight (ascent and descent) by comparing the barometric 


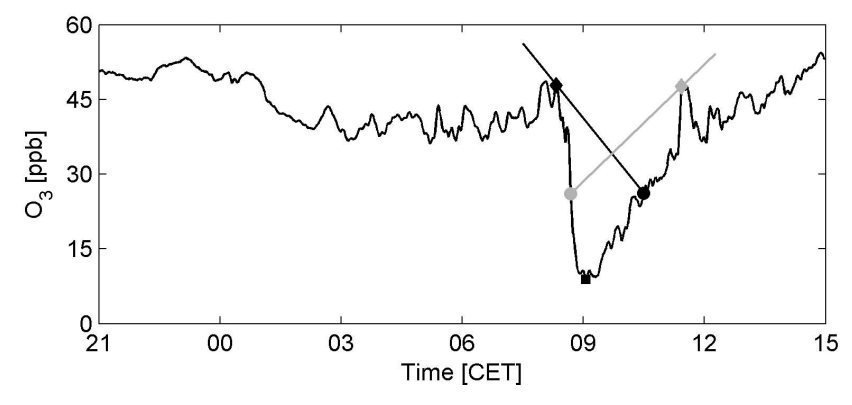

Fig. 2. Course of $\mathrm{O}_{3}$ mixing ratio at 5 September 2005 at the TOP station. The principal operation of the detection algorithm described in Sect. 2.5 is also shown. The black square indicates the detected minimum, the black and grey dots at the peak flank give the half peak values. The intercept of the grey straight line with the time series after the minimum indicates the end of the event (grey diamond), the intercept of the black straight line with the time series before the minimum marks the begin of the event (black diamond).

pressure readings from the sondes against the pressure of the ground based weather station. Drifts of the pressure derived altitude were distributed linearly over the preceding flight. As a last step, the corresponding altitude for each data point was calculated by stepwise solving the barometric formula. After each pair of ascent and descent, the final height deviation from 0 (i.e. ground level), which is a result of the discrete computation, was distributed linearly over the preceding flight. $\mathrm{CO}_{2}$ data were corrected for changing barometric pressure, a temperature correction was not applied, as the $\mathrm{CO}_{2}$ and the $\mathrm{O}_{3}$ sensor perform an online temperature correction $\left(\mathrm{O}_{3}\right.$ also pressure correction).

\subsection{Computed parameters}

Additional supporting parameters were derived from the measured quantities, such as for atmospheric stability. To assess the state of atmospheric stability, the dimensionless stability parameter $\zeta=\mathrm{z} / \mathrm{L}$ was used, where $\mathrm{z}$ is the height of measurement and $\mathrm{L}$ is the Obukhov length, calculated according to Eq. (1).

$$
\mathrm{L}=-\frac{\mathrm{u}_{*}^{3}}{\kappa \frac{\mathrm{g}}{\mathrm{T}_{\mathrm{V}}} \frac{\mathrm{Q}_{\mathrm{HB}}}{\rho \cdot \mathrm{c}_{\mathrm{p}}}}
$$

Here, $u_{*}$ is the friction velocity, $\kappa$ is the von-Kármán constant, $\mathrm{g}$ is the acceleration due to gravity, $\mathrm{T}_{\mathrm{V}}$ is the virtual air temperature, $\mathrm{Q}_{\mathrm{HB}}$ is the buoyancy flux, $\rho$ is the air density, and $c_{p}$ is the specific heat of air at constant pressure. Usually, $\mathrm{L}$ is computed by using the sensible heat flux and air temperature. However, we explicitly used the buoyancy flux and the virtual temperature instead, as the high humidity is expected to play a major role in atmospheric stability in the morning hours, the period of focus. From the equation of turbulent kinetic energy (see e.g. Stull, 1988) it follows that for $\zeta<-1$ the buoyancy term is dominant compared to the shear term, which is a precondition for free convection.

The height of the convective boundary layer (CBL) was determined from SODAR-RASS data by applying (1) the parcel method to profiles of air temperature (Holzworth, 1967, 1964) and (2) a method described by Beyrich (1997) to profiles of backscatter intensity.

\subsection{Investigation of long-term (monitoring) measurements}

A dataset extending over 5 years (October 2000-December 2005), obtained at the TOP station, was investigated for the occurrence of $\mathrm{O}_{3}$ drop events. This was done to determine if the SALSA field observations were the result of an exceptional situation, or if similar events occur frequently at the Hohenpeissenberg observatory. An automated detection scheme was developed and applied to the time series of the $\mathrm{O}_{3}$ mixing ratio ( $1 \mathrm{~min}$ resolution). This detection was conducted as follows: (1) a moving minimum was computed, comprising $\pm 180 \mathrm{~min}$ around the current value of the $\mathrm{O}_{3}$ time series. The time of the actual occurrence of the minimum was taken as input data for subsequent filtering procedures (Fig. 2, black square). (2) To ensure a clear separation of $\mathrm{O}_{3}$ minima, only detected minima with a temporal spacing of at least 60 min were investigated. (3) Half drop values were computed by considering the detected minimum values and the median $\mathrm{O}_{3}$ mixing ratios within 90 to $30 \mathrm{~min}$ before the minimum (Fig. 2, black and grey dots). (4) The detection of the onset of $\mathrm{O}_{3}$ drop event was done with a geometrical approach. For that, virtual lines were constructed from the point, where the rising flank of the $\mathrm{O}_{3}$ drop reached its half drop value after the minimum to data points prior to the event. The data point in the time series, corresponding to the virtual line with most negative slope, was taken as preliminary point of onset. The first local maximum of $\mathrm{O}_{3}$ before this point was taken as final point of the onset of the $\mathrm{O}_{3}$ drop event. A similar approach was used for determination of the end of the $\mathrm{O}_{3}$ drop event, using the half event value at the falling flank of the $\mathrm{O}_{3}$ drop, and a maximum positive slope criterion (see Fig. 2 for clarification). These geometrical approaches were chosen, because the $\mathrm{O}_{3}$ drops can also occur during changing background levels of $\mathrm{O}_{3}$, making a detection based on fixed thresholds impossible. Furthermore, all events detected by this scheme were subsequently filtered: (1) the minimum had to be more than $5 \mathrm{ppb}$ below the value at begin and end of the event; (2) the $\mathrm{O}_{3}$ level at the end of the event had to be within $\pm 25 \%$ and \pm standard deviation of the $\mathrm{O}_{3}$ level before the event; (3) the relative $\mathrm{O}_{3}$ drop had to exceed $10 \%$ of the previous $\mathrm{O}_{3}$ level; (4) the corresponding value of $\mathrm{NO}$ mixing ratio at the $\mathrm{O}_{3}$ minimum had to exceed its pre-event level plus standard deviation, and had to reach at least $0.5 \mathrm{ppb}$. The last criterion was introduced to limit the detection to $\mathrm{O}_{3}$ drop events with characteristics similar to those observed during the SALSA campaign. 
Table 2. Characteristics of $\mathrm{O}_{3}$ drop events. Event durations are defined as the span of time during which the $\mathrm{O}_{3}$ level remains below $50 \%$ of maximum drop intensity (full width of half event maximum). Minimum $\mathrm{O}_{3}$ shows the $\mathrm{O}_{3}$ mixing ratio at event maximum, the relative $\mathrm{O}_{3}$ decrease gives the percentage of initially present $\mathrm{O}_{3}$ being missed during the event.

\begin{tabular}{|c|c|c|c|c|c|c|}
\hline & 30 Aug & 31 Aug & 3 Sep & 5 Sep & $7 \mathrm{Sep}$ & 8 Sep \\
\hline Onset time (CET) & 08:00 & 09:00 & $08: 15$ & $08: 30$ & 09:15 & $09: 30$ \\
\hline Peak time (CET) & 08:30 & 10:30 & $08: 54$ & 09:05 & 09:48 & 09:50 \\
\hline Duration [minutes] & 13 & 71 & 27 & 118 & 15 & 10 \\
\hline Initial $\mathrm{O}_{3}$ level $[\mathrm{ppb}]$ & 45 & 45 & 48 & 41 & 46 & 48 \\
\hline Minimum $\mathrm{O}_{3}$ level [ppb] & 27 & 20 & 22 & 7 & 19 & 37 \\
\hline Relative $\mathrm{O}_{3}$ decrease [\%] & 40 & 56 & 54 & 81 & 59 & 23 \\
\hline Initial NO level [ppb] & 0.2 & 0.4 & 0.1 & 0.1 & 0.1 & 0.2 \\
\hline Maximum NO level [ppb] & 0.7 & 6.1 & 1.4 & 12.7 & 4.1 & 0.7 \\
\hline Initial specific humidity $\left[\mathrm{g} \mathrm{kg}^{-1}\right]$ & 11.1 & 12.2 & 11.3 & 8.8 & 7.1 & 8.6 \\
\hline Maximum specific humidity $\left[\mathrm{g} \mathrm{kg}^{-1}\right]$ & 11.7 & 14.0 & 12.2 & 11.1 & 11.4 & 10.1 \\
\hline$\phi$ before event $\left[{ }^{\circ}\right]$ & 90 & 180 & 90 & 180 & 180 & 180 \\
\hline$\phi$ after event $\left[{ }^{\circ}\right]$ & 50 & 360 & 30 & 45 & 45 & 50 \\
\hline $\mathrm{v}_{h}$ minimum observed? & Yes & No & Yes & Yes & Yes & Yes \\
\hline
\end{tabular}

An index, whether or not a mesoscale circulation system called Alpine Pumping (see Lugauer and Winkler (2005); also described below) was active at a certain day, was computed by checking the South-North wind component (V). If it changed from positive values before $06: 00 \mathrm{~h}$ to negative values after 12:00 h, while the total global radiation exceeded $20 \mathrm{MJ} \mathrm{m}^{-2}$ at this day, Alpine Pumping was assumed to be active.

\section{Results}

This chapter is subdivided into five parts. First, a typical "event" course of $\mathrm{O}_{3}$ mixing ratio at the TOP station in the morning hours is presented. Then we describe the general characteristics of all observed events during the SALSA campaign. Third, mean diurnal cycles of the flow characteristics for a subgroup of three events are presented. Fourth, we focus on the strongest event within this subgroup (as a case study) and describe its characteristics as observed at TOP station, within the ABL and at the BASE. Fifth, the frequency of $\mathrm{O}_{3}$ mixing ratio drop at the TOP station is determined by inspecting a more than 5 years dataset. All times and dates are given in the following are Central European Time $(\mathrm{CET}=\mathrm{UTC}+1 \mathrm{~h})$.

\subsection{The $\mathrm{O}_{3}$ drop events}

On several days during the SALSA campaign, a significant negative excursion of $\mathrm{O}_{3}$ mixing ratio at the TOP station has been observed. An example is shown in Fig. 2. Although not every observed event was as strong as that on 5 September 2005 , they were always a significant deviation from the expected (quasi constant) mixing ratio of $\mathrm{O}_{3}$ at the TOP station.
Further analyses revealed that the $\mathrm{O}_{3}$ events were associated with a couple of other distinctive features, which will be presented in the following.

\subsection{General characteristics}

A total number of six $\mathrm{O}_{3}$ drop events were observed during the SALSA campaign (22 August-23 September 2005). The event durations ranged from 10 to $118 \mathrm{~min}$ (defined as the span of time during which $\mathrm{O}_{3}$ levels remained below the half drop value). The observed $\mathrm{O}_{3}$ reductions ranged from 23 to $80 \%$ of the initially present $\mathrm{O}_{3}$. Characteristics of the $\mathrm{O}_{3}$ drop events are summarized in Table 2.

No correlation was found between the event duration and its intensity. All event days had almost clear skies during the morning, except for 3 September 2005, when a considerable number of cumulus clouds were present. The irradiated shortwave energy from 00:00 $\mathrm{h}$ until the onset of the event, ranged between $1.8 \mathrm{MJ} \mathrm{m}^{-2}$ and $2.4 \mathrm{MJ} \mathrm{m}^{-2}$, depending on the onset time and the presence of scattered clouds. Neither the event duration nor the $\mathrm{O}_{3}$ decrease intensity correlated with the irradiated energy.

All of the observed events occurred at low wind speeds, in five cases there was a distinct wind speed minimum, lasting 2 to $3 \mathrm{~h}$. In three cases, a sudden change of wind direction during the event was observed. Wind direction before the event was around south, after the event wind came from northeastern directions. Two other events were characterised by more or less stable wind directions around east, while the last event was accompanied by a continuously turning wind from east at midnight over south in the early morning to west at the time of the event and then continuing over north to east again in the evening. 

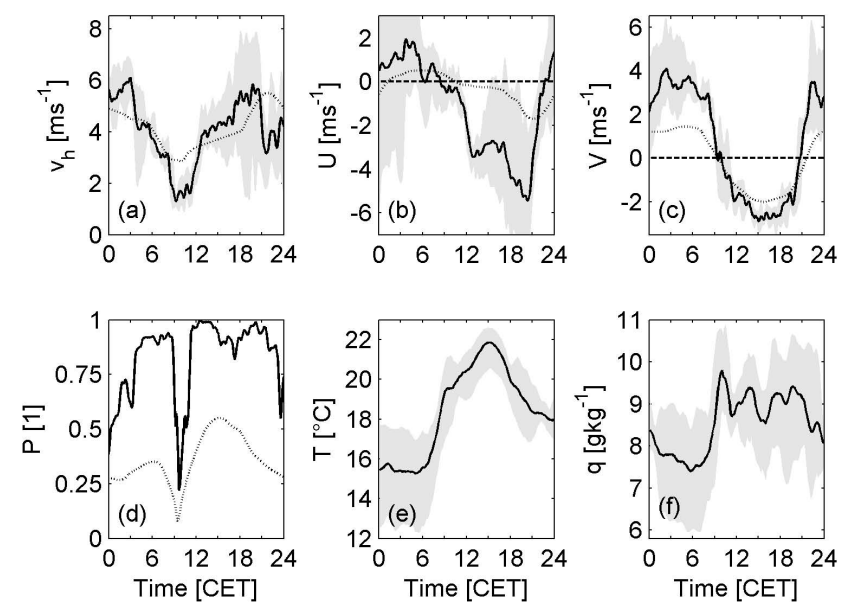

Fig. 3. Mean diurnal course of (a) scalar horizontal wind speed $\mathrm{v}_{h}$, (b) west-east wind component $\mathrm{U}$, (c) south-north wind component $\mathrm{V}$, (d) persistence of wind direction $\mathrm{P}$, (e) air temperature $\mathrm{T}$ and (f) specific humidity $\mathrm{q}$ at TOP station for the last three event days $(5$, 7, and 8 September 2005). The grey shaded area gives the absolute range of values, the dotted line shows the corresponding result reported by Lugauer and Winkler (2005).

\subsection{Mean characteristics}

From the wind characteristics of the six observed $\mathrm{O}_{3}$ events (Table 2), a group of three $\mathrm{O}_{3}$ depletion events with more or less similar flow patterns can be discerned. These are the last three events observed during the experiment $(5,7$ and 8 September 2005). For this group, the mean diurnal course of the wind velocity and the absolute range of values were computed. The latter demonstrates the quasi identical flow regime on all three days. Figure 3 shows the mean diurnal course of horizontal wind speed $\left(\mathrm{v}_{h}\right)$, its west-east and southnorth components ( $\mathrm{U}$ and $\mathrm{V}$, respectively), and the degree of persistence $(\mathrm{P})$ of the wind direction at any time of the day. Additionally, the mean diurnal cycle of air temperature and specific humidity are displayed. The calculation of $\mathrm{P}$ is done according to Lugauer and Winkler (2005), following Eq. (2), where $P$ is defined as the temporal vector mean of the horizontal wind speed divided by the temporal arithmetic mean of the horizontal wind speed at any time of the day.

$\mathrm{P}(\mathrm{t})=\frac{\sqrt{\overline{\mathrm{U}(\mathrm{t})}^{2}}+\sqrt{\overline{\mathrm{V}(\mathrm{t})}^{2}}}{\overline{\mathrm{Vh}_{\mathrm{h}}(\mathrm{t})}}$

A value for $\mathrm{P}$ of 1 indicates that every day at that time the wind blew from the same direction, a value of 0 indicates that at that time all wind directions occurred at the same frequency.

A distinct, absolute minimum of $\mathrm{v}_{\mathrm{h}}$ (Fig. 3a) can be observed around 09:00 $\mathrm{h}$ to $11: 00 \mathrm{~h}$ in the morning. Additionally, P (Fig. 3d) approaches its minimum at the same time, indicating highly variable wind directions during that period.
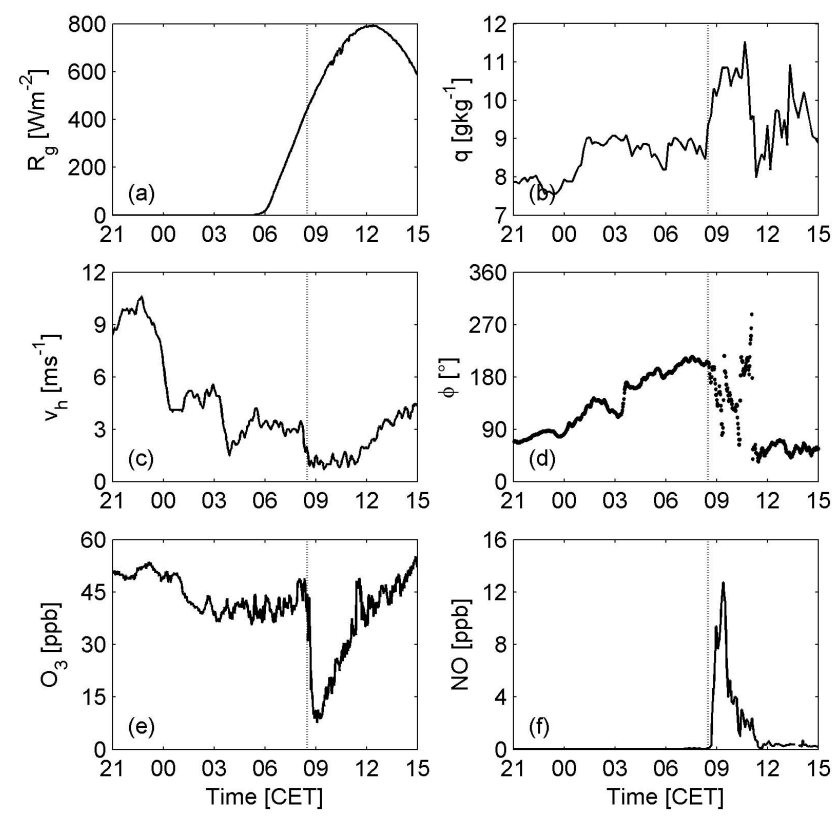

Fig. 4. Hohenpeissenberg observatory (TOP station), 4 September 2005, 21:00 h to 5 September 2005, 15:00 h, diurnal variations of: course of (a) global radiation $\mathrm{R}_{g}$, (b) specific humidity q, (c) horizontal wind speed $\mathrm{v}_{h}$, (d) wind direction $\phi$, (e) ozone mixing ratio $\mathrm{O}_{3}$ and (f) nitric oxide mixing ratio NO. Note the coinciding change of wind direction and the drop of $\mathrm{O}_{3}$ mixing ratio together with the peak of NO mixing ratio. The dashed line indicates the onset of the $\mathrm{O}_{3}$ event.

The quasi reversal of the mean flow becomes especially visible in the vector component $\mathrm{V}$ (Fig. 3c), where a fast change from southern directions (positive values) to northern directions (negative values) is obvious around that time. Coincidentally with the flow reversal, a period of stagnant or even falling air temperature is visible (Fig. 3e), while the specific humidity (Fig. 3f) reaches its maximum values.

To get better insight into the potential processes being active in the ABL on these days, we now focus on the day with the strongest occurrence of the $\mathrm{O}_{3}$ drop at TOP station, namely the 5 September 2005 . This event was selected, as all accompanying processes are expected to be best observable during the most intensive event.

\subsection{September 2005: Case study}

The 5 September 2005 was a clear, sunny and warm day. The global radiation $\mathrm{R}_{g}$ at TOP station (Fig. 4a), showed a nearly perfect bell-shaped curve in the absence of clouds. The specific humidity q at the TOP station (Fig. 4b) varied only slightly during the night and early morning. Shortly before 09:00 h, it increased rapidly from about $9 \mathrm{~g} \mathrm{~kg}^{-1}$ to $11 \mathrm{~g} \mathrm{~kg}^{-1}$. Around 11:00 h, the specific humidity dropped, but remained very variable during the afternoon. The horizontal wind speed $\mathrm{v}_{h}$ at the mountain summit (Fig. 4c) 
decreased from higher night time values to a minimum around 09:00 h, while slightly increasing again from afternoon to evening. The wind direction (Fig. 4d) changed slowly from east to south during the night and early morning, until around 09:00 $\mathrm{h}$ when an abrupt change to easterly directions occurred. After 11:00 h, the wind direction remained around north-east. $\mathrm{O}_{3}$ mixing ratios (Fig. 4e) were quasi constant during night within a range of 40 to $50 \mathrm{ppb}$. Together with the change of wind direction around 09:00 h mixing ratios collapsed to $7 \mathrm{ppb}$ and recovered during the following three hours. Coincidentally, NO mixing ratios increased from below the detection limit to $12 \mathrm{ppb}$ and decreased during the following hours (Fig. 4f).

The presence of SODAR-RASS and tethered balloon systems provided the unique chance of observing the state of the ABL up to well above the mountain summit with respect to wind, turbulence, air temperature and the mixing ratios of the trace gases $\mathrm{CO}_{2}, \mathrm{O}_{3}$ and $\mathrm{H}_{2} \mathrm{O}$. Figure 5 presents time-height cross sections of wind direction $\phi$ (Fig. 5a), horizontal wind speed $\mathrm{v}_{h}$ (Fig. 5b) and potential air temperature $\theta$ (Fig. 5c), all for the interval from 4 September, 21:00 $\mathrm{h}$ to 5 September 2005, 15:00 h.

In the lowest $130 \mathrm{~m}$, a layer with westerly winds developed during the night (Fig. 5a), beginning around 23:00 $\mathrm{h}$ in the evening. The different wind direction within this layer (compared to the layer above) indicated that it was completely decoupled from the air above. The lower layer was the nocturnal boundary layer, while the upper one was the residual layer. The nocturnal boundary layer reached its maximum vertical extent shortly after 03:00 $\mathrm{h}$ in the morning. At this time, wind direction changed also in higher altitudes from easterly to southerly directions. A distinct spatial boundary with respect to directional wind shear, was no longer observable from this time on. After sunrise around 06:00 h, the entire observable ABL was characterized by a smooth transition from westerly winds close to the ground to southerly wind directions above $300 \mathrm{~m}$ a.g.l. Shortly after $08: 00 \mathrm{~h}$, the wind changed abruptly to easterly directions. This change affected all levels in the lowest $200 \mathrm{~m}$ at the same time, while the change was gradually delayed at higher altitudes.

Coinciding with the change of wind direction, the horizontal wind speed (Fig. 5b) dropped to very low values $\left(<1 \mathrm{~m} \mathrm{~s}^{-1}\right)$. These low wind speeds prevailed only shortly in the lowest $200 \mathrm{~m}$ of the atmosphere, being followed by stronger fluctuations with peak values of approx. $4 \mathrm{~m} \mathrm{~s}^{-1}$. Above $200 \mathrm{~m}$ a.g.l., the calm period lasted considerably longer and the onset of the fluctuations was delayed by approximately two hours. The last parameter of the SODARRASS system considered here is the potential air temperature $\theta$ (Fig. 5c). Starting in the late evening, a very stable thermal stratification of the ABL developed by radiative cooling of the surface. A gradual increase of $\theta$ in the entire profile was interrupted around 09:00 $\mathrm{h}$ by a temperature drop. It became first visible close to the ground, but affected the entire observable atmosphere within half an hour. After that, the
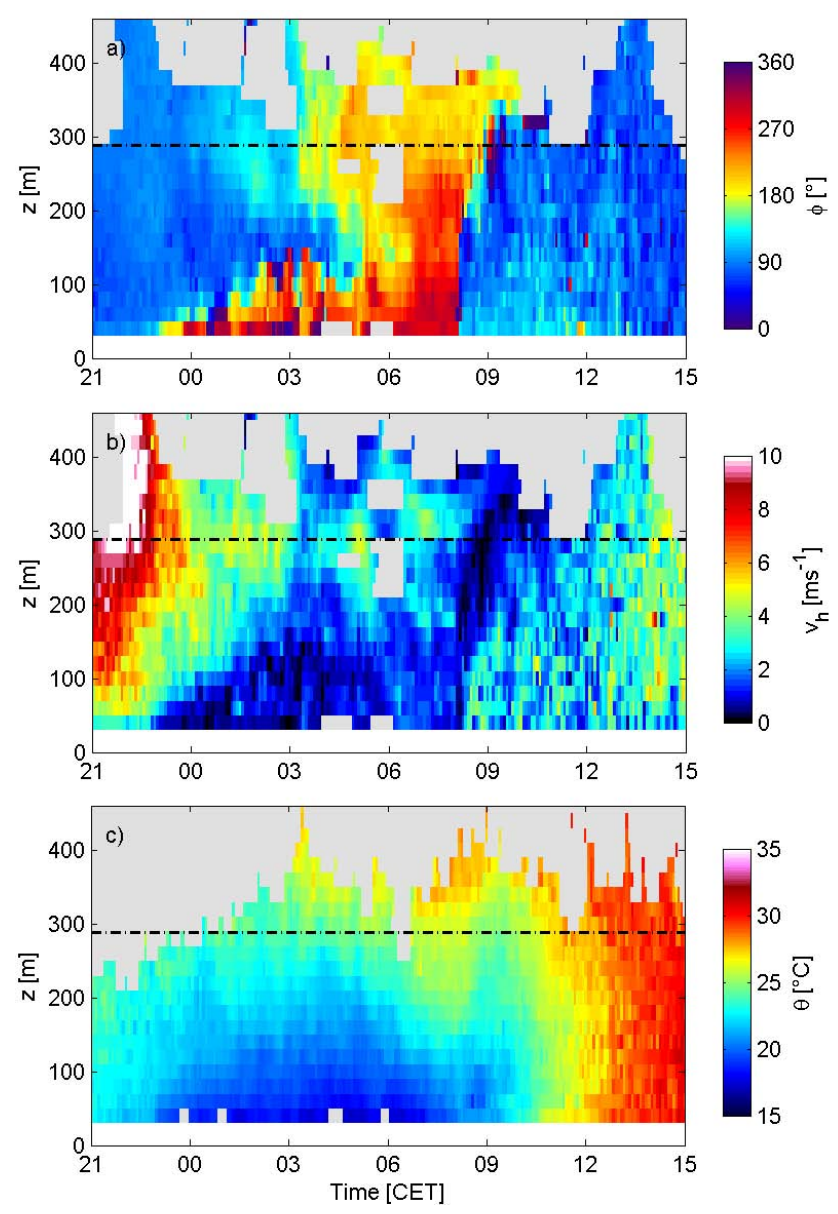

Fig. 5. Time-height cross sections of (a) wind direction $\phi$, (b) horizontal wind speed $\mathrm{v}_{h}$, and (c) potential air temperature $\theta$, measured by SODAR-RASS, from 4 September 21:00 h to 5 September 15:00 $\mathrm{h}$. The dash-dotted line marks the altitude of the TOP station. Note around 09:00 $\mathrm{h}$ the sudden change of wind direction in (a), the pronounced minimum of horizontal wind speed around the altitude of TOP in (b), and the temperature drop within the entire ABL in (c).

ongoing solar heating of the ground led to the development of a thermally unstable ABL.

The height of the boundary layer BL ( $\mathrm{z}_{\mathrm{BL}}$ ) was determined from $15 \mathrm{~min}$ average profiles of $\theta$ using the parcel method (Holzworth, 1964 and 1967) and from half-hourly average profiles of the reflectivity of the vertical acoustical antenna by visual inspection. A secondary maximum of reflectivity indicates the BL height (Beyrich, 1997). Both methods yielded similar BL heights (Fig. 6) with a maximum of $380 \mathrm{~m}$ a.g.1. at 13:30 h. The onset of the evolution of the convective boundary layer CBL detected by the parcel method (09:00 h) was one hour later than inferred from the reflectivity data $(08: 00 \mathrm{~h})$. Growth rates of the CBL were around $50 \mathrm{~m} \mathrm{~h}^{-1}$ with both methods. The height of the CBL reached the TOP station around 12:00 h, that means, the TOP station 


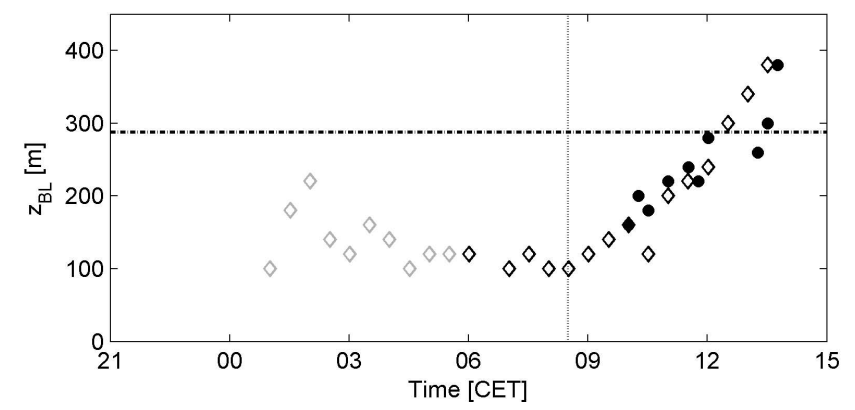

Fig. 6. Development of the BL height $\left(\mathrm{z}_{\mathrm{BL}}\right)$, from 4 September 21:00 h to 5 September 15:00 h, derived from the parcel method (dots) and from secondary maximum of reflectivity (open diamonds). Grey diamonds indicate nocturnal inversion height, black diamonds indicate CBL height. The dash-dotted line marks the altitude of the TOP station, the dotted line indicates the onset of the $\mathrm{O}_{3}$ decrease at the TOP station.

was clearly outside the CBL around 09:00 h.

Besides the profiles with high temporal resolution obtained by the SODAR-RASS system, profile data from the tethered balloon system were available for the morning hours of 5 September 2005. The system was operated in scanning mode, i.e. the profiles were obtained by raising and lowering the balloon continuously. The scanning mode provided a good spatial resolution but with some temporal ambiguity in the profiles, resulting from the time needed for a complete scan. The main advantage of the tethered balloon system was its ability to measure profiles of the trace gases $\mathrm{CO}_{2}, \mathrm{O}_{3}$ and the specific humidity q besides the meteorological data. However, trace gas data added invaluable information to the profiles obtained by the SODAR-RASS system. By chance, one of these scanned profiles at 5 September 2005 captured the event and gave insight into its vertical structure. A set of time-height cross sections and profiles for $\mathrm{q}, \mathrm{O}_{3}, \mathrm{CO}_{2}$ and $\theta$ is shown in Fig. 7. The time-height cross sections of q, $\mathrm{O}_{3}$, $\mathrm{CO}_{2}$ and $\theta$ (Fig. 7a-d) show a growing but clearly confined layer of higher $\mathrm{q}$ and $\mathrm{CO}_{2}$ and lower $\mathrm{O}_{3}$ and $\theta$ compared to the air above from about 07:30 h. After 09:30 h, in the last descent of the tethered balloon, this confinement was no longer visible. In Fig. 7d $(\theta)$, a pool of cold, nocturnal air close to the ground could be identified. Between 07:00 $\mathrm{h}$ and 08:00 h, this surface air rapidly warmed up, but still remained colder than the air above.

The profiles on the right side of Fig. 7 depict the upward scan of the tethered balloon at the time of the $\mathrm{O}_{3}$ drop at TOP station. All profiles could be divided into the following segments: (1) a lower part up to $130 \mathrm{~m}$ a.g.l. with almost constant values for all parameters, capped by a temperature inversion (Fig. 7d), which resulted in a drop of $\mathrm{q}$ and also of $\mathrm{CO}_{2}$, whereas $\mathrm{O}_{3}$ started to increase from this altitude on (this layer coincided very well with the CBL determined from the SODAR-RASS data); (2) at $290 \mathrm{~m}$ a.g.l., a distinct layer of approx. $30 \mathrm{~m}$ thickness became obvious, being char-
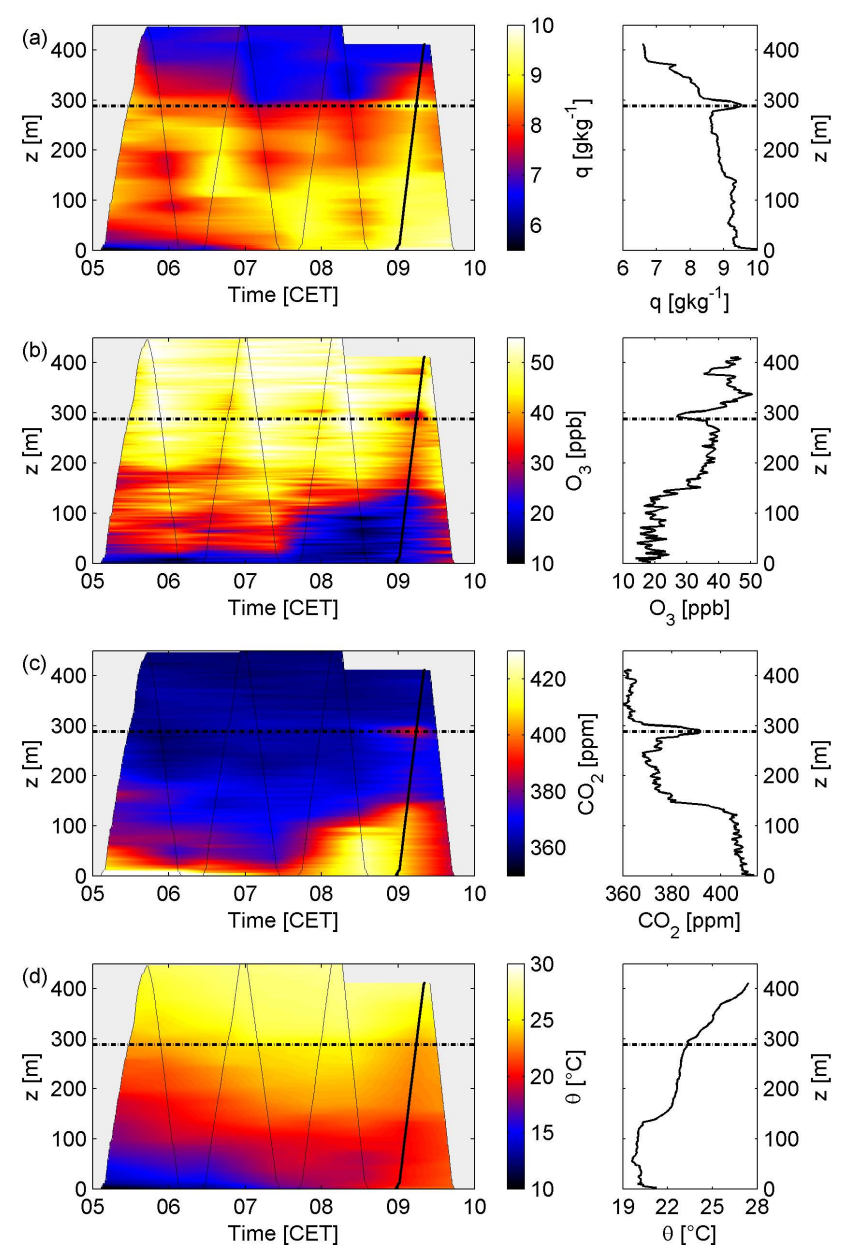

Fig. 7. Time-height cross sections and profiles of (a) specific humidity q, (b) $\mathrm{O}_{3}$ mixing ratio, (c) $\mathrm{CO}_{2}$ mixing ratio, and (d) potential temperature $\theta$ for the morning of 5 September 2005. The actual flight path of the tethered balloon is indicated by the thin black line. Profiles on the right side show the upward scan of the tethered balloon at the time when the $\mathrm{O}_{3}$ drop reached the TOP station (corresponding to the actual flight path marked with a thick black line).

acterized by enhanced water content, higher $\mathrm{CO}_{2}$ values and by a reduced $\mathrm{O}_{3}$ level; (3) at the top of the profiles at $420 \mathrm{~m}$ a.g.l., the trace gases $\mathrm{CO}_{2}$ and $\mathrm{O}_{3}$ reached typical lower tropospherical background levels of $360 \mathrm{ppm}$ and $50 \mathrm{ppb}$, respectively, while q reached approx. $6.5 \mathrm{~g} \mathrm{~kg}^{-1}$.

After the temporal and spatial changes within the ABL have been described in detail, the observations at the BASE will be examined.

The characteristics of the wind at the BASE with respect to speed and direction were comparable to that within the ABL, especially the sudden change of the flow direction around 09:00 h (see Fig. 8c, d). Following the cold night, the sensible heat flux started to increase shortly after sunrise (Fig. 8a) together with increasing air temperature 

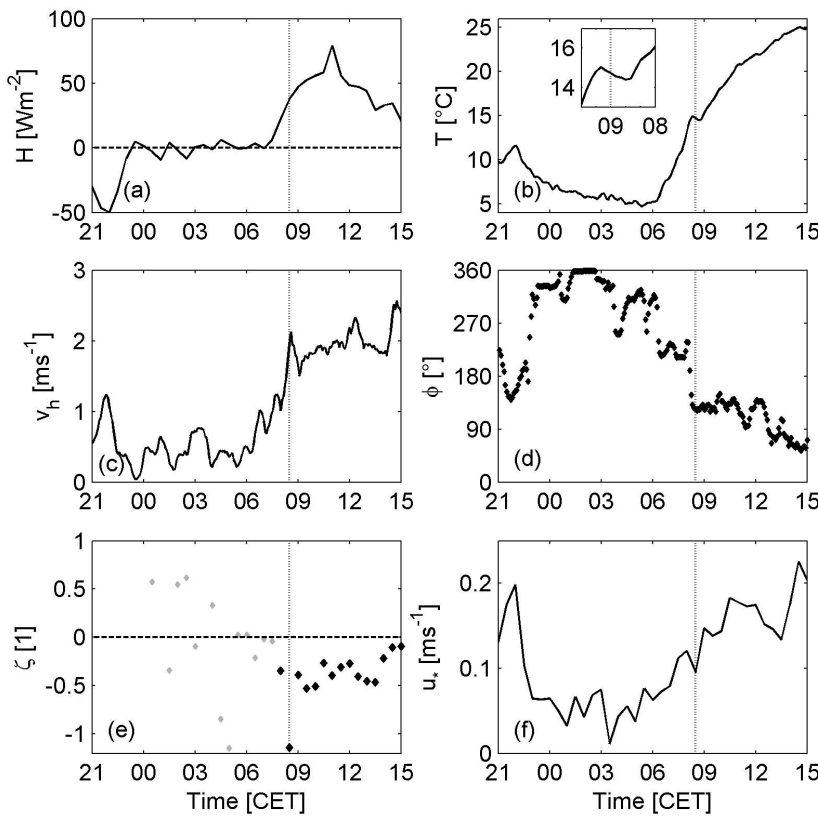

Fig. 8. Course of (a) sensible heat flux $H$, (b) air temperature $T$ (exceptional drop of T enlarged), (c) horizontal wind speed $\mathrm{v}_{h},(\mathbf{d})$ wind direction $\phi$, (e) stability parameter $\zeta$ and (f) friction velocity $u_{*}$ from 4 September 21:00 $\mathrm{h}$ to 5 September 15:00 $\mathrm{h}$ at BASE. Grey dots for $\zeta$ denote low quality of $\zeta$ due to low sensible heat flux $(-10<\mathrm{H}<10)$, black dots for $\zeta$ indicate high quality of derived $\zeta$ values. The dashed line indicates the onset of the $\mathrm{O}_{3}$ event at the TOP station.

(Fig. 8b). The relative humidity at the BASE (not shown) dropped down from saturation almost $1 \mathrm{~h}$ before the onset of the event. With the onset of the event, a clear drop of air temperature was observed, lasting for almost one hour. The time of the temperature decrease coincided well with the temperature decrease of the entire ABL, observed by the SODAR-RASS system (Fig. 5c). The stability parameter $\zeta$ (Fig. 8e), being valid for the surface layer, showed mostly positive values during night, indicating stable conditions. But with $\mathrm{H}$ around zero, values of $\zeta$ were of low quality and had to be considered with care. The most unstable situation within the surface layer was found around 08:30 h, when $\zeta$ reached values of -1.2 . Later towards noon, unstable conditions prevailed $(\zeta \approx-0.3)$. Friction velocity $u_{*}$ (Fig. 8f) was slightly increased from its night time values $\left(\approx 0 \mathrm{~m} \mathrm{~s}^{-1}\right)$, and reached only small secondary minimum values $\left(\approx 0.1 \mathrm{~m} \mathrm{~s}^{-1}\right)$ at 09:00 h. The conditions needed for free convection were met (Stull, 1988) with the increasing buoyancy due to increasing sensible heat flux, and the decreasing shear, indicated by low $u_{*}$ values. $\mathrm{O}_{3}$ mixing ratio decreased during night at the BASE to zero (not shown here). With increasing insolation and developing turbulence, it started to increase until shortly before 09:00 $\mathrm{h}$, when a decline to the low nocturnal values occurred. The later increase of $\mathrm{O}_{3}$ mixing ratio was again interrupted around $10: 30 \mathrm{~h}$, when $\mathrm{O}_{3}$ mixing ratio remained for approximately two hours at a more or

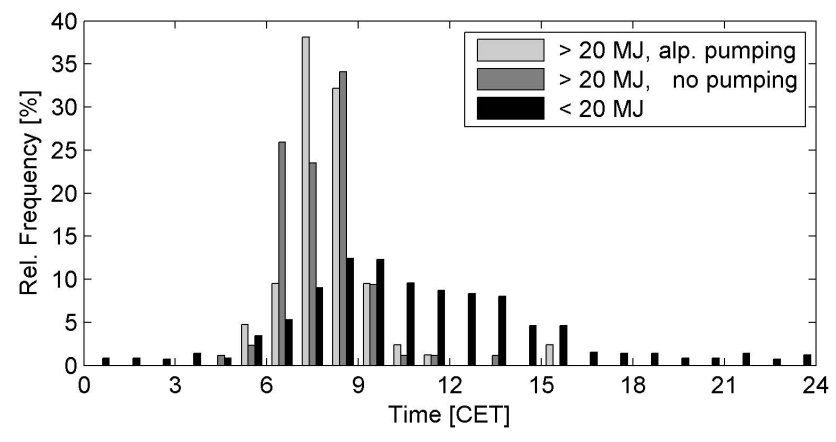

Fig. 9. Diurnal variation of relative frequency of $\mathrm{O}_{3}$ events for days with high irradiation and Alpine Pumping (light grey, $N=84$ ), with high irradiation but without Alpine Pumping (dark grey, $N=85$ ) and for days with total irradiated energy of less than $20 \mathrm{MJ} \mathrm{m}^{-2}$ (black, $N=587$ ).

less constant level.

\subsection{Long dataset}

After the detailed investigation of the observations coinciding with the $\mathrm{O}_{3}$ drop at TOP station, within the ABL, and at the BASE, we also evaluated a 5 year dataset (October 2000 to December 2005) of the TOP station for the occurrence of sudden $\mathrm{O}_{3}$ decreases. As the events observed during the SALSA experiment were restricted to days with high irradiation, we split the analysis into days with total irradiated energy exceeding $20 \mathrm{MJ} \mathrm{m}^{-2}$ and days with less energy input. The radiation days were further subdivided into days with and without Alpine Pumping. The resulting diurnal histogram is shown in Fig. 9. The class with low radiation shows a smooth distribution curve, with highest values between 08:00 h and 10:00 h. During night, only few events were detected. Both classes with high irradiated energy were characterized by a sharp peak in the early morning, with maximum frequencies between 08:00 h and 09:00 h. Almost no events were found in the afternoon and during night time.

\section{Discussion}

At a first glance, several explanations for the $\mathrm{O}_{3}$ drop events seem to be possible from our observations. "Transport" is common to all of them, however varying in important aspects. It is known from earlier studies (Lugauer and Winkler, 2005) that the region of the SALSA experiment is occasionally affected by a mesoscale circulation system between the Alps and their northern foreland (Alpine Pumping). Whether or not this circulation was present during the experiment and whether it impacts the observations will be discussed in the first section. 
The variability of the $\mathrm{O}_{3}$ drop intensity, its peak time and its event duration (see Table 2) suggest highly dynamical processes behind this phenomenon. A number of processes leading to the observed $\mathrm{O}_{3}$ drop events are conceivable: (1) a local, temporally limited $\mathrm{O}_{3}$ sink close to the mountain summit, (2) a local valley-to-mountain circulation, including the influence from a national road passing the foot of the mountain in east-west direction, (3) change of air masses (passage of fronts), (4) immersion of the mountain summit into the developing convective boundary layer, and (5) direct injection of air masses by free convection from the foot of the mountain into higher ABL altitudes. From the observations presented in the results chapter, we will demonstrate that it is possible to narrow the number of these processes down to one final explanation: free convection. For that, after a brief description of the mesoscale circulation system "Alpine Pumping", we will start with the most local process and will increase the spatial dimension step by step.

\subsection{Mesoscale circulation system - Alpine Pumping}

On days of high solar irradiance, barometric pressure in the valleys of the Alps becomes low relative to the Alpine foreland due to enhanced heating up of the valley air. This horizontal pressure difference forces air during day time to flow from the foreland plains towards the mountains of the Alps, where it rises convectively. The diurnal counter flow from mountain to foreland occurs at higher altitudes. For dynamical reasons, it causes a subsidence over the foreland with typically cloud free skies. During night time, stronger cooling in the valleys leads to higher barometric pressure in the valleys, resulting in an outflow of air towards the foreland plains (Whiteman and Bian, 1998; Whiteman, 2000).

The influence of thermally driven wind systems in the area of the SALSA experiment was intensively investigated by Lugauer and Winkler (2005). The diurnal oscillation of the wind direction, caused by the heating and cooling of the Alps, was found to affect the Alpine foreland up to $100 \mathrm{~km}$ to the north with a vertical extent of $1 \mathrm{~km}$ at the Alpine margin. From 340 days with strong irradiation (out of 5 years), Lugauer and Winkler (2005) calculated mean diurnal cycles of horizontal wind speed, west-east and south-north wind components and the persistence of wind direction at the Hohenpeissenberg summit.

The comparison of the mean diurnal cycles from Lugauer and Winkler (2005) with mean diurnal cycles from the SALSA experiment (Fig. 3) reveals a striking similarity, although our results are only based on 3 days. Nevertheless, for these 3 days, we can assume that a similar flow regime, the Alpine Pumping, was dominating the experimental site. Additionally, in accordance with Lugauer and Winkler (2005), a slight delay of the wind direction change in higher altitudes occurred compared to the surface layer (Fig. 5a). This was in agreement with the typical speed at which this circulation system develops.
A fast change of wind direction, especially when it comes close to a flow reversal, always implies a period of low to zero wind speed. With the Alpine Pumping starting to affect the TOP station (indicated by the South-North wind component $(\mathrm{V})$ changing from positive to negative values), such calm conditions were found. They lasted from a few minutes up to more than half an hour. This is noteworthy, as low horizontal wind speeds can trigger some of the processes discussed in the following (i.e. free convection).

\subsection{Local sink for $\mathrm{O}_{3}$ at mountain summit}

Strong local sinks for $\mathrm{O}_{3}$ within $300 \mathrm{~m}$ to the TOP station, which could facilitate a substantial drop of $\mathrm{O}_{3}$ mixing ratio at the TOP station, can be excluded. Adverse (chemical) effects of the station itself (exhaust from lab vents etc.) are not likely, since the setup of the observatory as a background trace gas measurement station of the Global Atmosphere Watch (GAW) program has to follow strict operational guidelines. In the unlikely case that some exhaust gas from cars in the parking lot at Hohenpeissenberg summit would have reached the gas sampling inlet, it would have resulted in a sharp but short $\mathrm{O}_{3}$ drop rather than in an $\mathrm{O}_{3}$ reduction lasting half an hour and more. Furthermore, this would happen only in the case of (local) wind directions around $90^{\circ}-100^{\circ}$. However, the mean annual frequency of these wind directions is less than 5\%. On 5 September 2005, the mean wind direction at the time of the onset of the $\mathrm{O}_{3}$ drop event was from south, so the parking lot was not upwind of the TOP station.

Having demonstrated that there was no current chemical destruction of $\mathrm{O}_{3}$ at the mountain summit, we will now focus on the area south of the mountain summit because, as concluded from the wind direction, the reason for the $\mathrm{O}_{3}$ drop must be located there.

\subsection{Valley-to-mountain circulation}

The high frequency of $\mathrm{O}_{3}$ drop events in the morning hours may point to a local, thermally driven, valley-to-mountain circulation at the Hohenpeissenberg mountain. The high solar irradiance and the partly deforested slope of the mountain would support this idea. Furthermore, the village of Hohenpeissenberg is located at the lower end of the deforested south flank of the mountain, and a national road passes by. Together, village and road would provide enough $\mathrm{O}_{3}$ destructors (mainly NO from heating and exhaust gases). But although this mechanism might seem to be the most probable one, several results of our measurements point into a different direction. 
First, at the SALSA forest station at the southern slope of the mountain, half way between the deforested area and the summit, the wind direction remained around North, which is a downhill flow, at mean wind speeds around $0.5 \mathrm{~m} \mathrm{~s}^{-1}$. From that, an upslope wind, at least in the trunk space of the forest, can be excluded.

Second, one of the vertical scans of the tethered balloon (Fig. 7, right panels) encountered an $\mathrm{O}_{3}$ poor layer at approx. $300 \mathrm{~m}$ a.g.l. on 5 September 2005, 09:16 h, which was shortly after the maximum intensity of the $\mathrm{O}_{3}$ drop at the TOP station. The tethered balloon profiles were measured in a horizontal distance of approx. $1.6 \mathrm{~km}$ from the TOP station (as referenced to the launching site of the balloon). Even with some northward drift of the balloon due to the southerly winds, the $\mathrm{O}_{3}$ poor air mass was detected still more than $1 \mathrm{~km}$ south of the summit. The wind direction from south (at the height of TOP) makes it impossible for an air mass being upslope transported by a valley-to-mountain circulation to be found $1 \mathrm{~km}$ south of the mountain summit. Under the assumption that the $\mathrm{O}_{3}$ poor air mass observed by the balloon is in coherence with the $\mathrm{O}_{3}$ event at the TOP station, which will be proven below, a local valley to mountain circulation has to be definitely excluded as the dominating process.

\subsection{Airmass change, passage of fronts}

The sudden drop of $\mathrm{O}_{3}$ mixing ratio at the TOP station, together with the change of wind direction, could suggest a change of air masses. But in this case, $\mathrm{O}_{3}$ values would have to stay low after the event and would not recover to values comparable to those before. Additionally, a peak in NO would not be expected, as NO must have been transported very fast towards the TOP site to not be converted into $\mathrm{NO}_{2}$ due to reaction with the present $\mathrm{O}_{3}$ during the transport. Instead, comparable levels of $\mathrm{O}_{3}$ mixing ratio were observed, and $\mathrm{NO}$ (Fig. 4f) as well as $\mathrm{NO}_{2}$ (not shown) dropped back to its pre event values close to 0 . This indicates that only a temporary excursion from the state prior to the event had occurred and not a general change. Furthermore, the sharp boundaries of the $\mathrm{O}_{3}$ depleted layer observed by the tethered balloon (Fig. 7b) suggest only a short transport time. Longer lasting transport would have smeared out the boundaries due to turbulent diffusion. Based on that, advection from greater distance, embedded in a different air mass, becomes highly unlikely. Around the $\mathrm{O}_{3}$ drop event, a slight cooling of the entire ABL was observable (Fig. 5c), although the irradiation remained undisturbed (Fig. 4a). Since coincidences are always eye-catching, and an air mass change can be excluded, an independent explanation for the cooling has to be found, preferably a process, comprising the cooling and the simultaneous presence of the $\mathrm{O}_{3}$ depleted layer. This could provide a proper explanation of the dynamics behind the $\mathrm{O}_{3}$ drop events. But before such an attempt will be made, other processes being relevant in the morning hours have to be examined (and finally excluded).

\subsection{Immersion of TOP station into CBL}

The altitude of the wind direction change (Fig. 5a) did not coincide with the height of the CBL at this time. Although the CBL growth started at the same time as the wind direction started to change at the BASE, its height was still about $150 \mathrm{~m}$ less than the altitude of the layer affected by wind direction change (i.e. the altitude, where the transition of wind direction before to the wind direction after the onset of Alpine Pumping actually occurred). In Fig. 5b, the CBL can be identified as the region of enhanced wind speed fluctuations, reaching values of around $5 \mathrm{~m} \mathrm{~s}^{-1}$ in the afternoon. An independent confirmation is given by Fig. 6, where the CBL height is derived from the profile of $\theta$, which gives the height up to which an air parcel may rise by buoyancy if released at the ground, as well as the CBL height derived by visual inspection of the reflectivity data. Compared to other fair weather days during the experiment (not shown here) the evolution of the CBL started late, the growth rate was much lower and the CBL height reached a very low maximum height. Growth rates of $100 \ldots 1000 \mathrm{~m} \mathrm{~h}^{-1}$ (Seibert et al., 1998) were reported and maximum heights of the CBL on the order of 1 to $2 \mathrm{~km}$ (Stull, 1988) can be expected on clear, sunny days over terrestrial surfaces in mid latitudes. The lateral heterogeneity of the land, with patches contributing more (grassland, villages) or less (forest, rivers, lakes) to the development of the CBL reduced the expected growth rates and maximum CBL height around the SALSA site. Furthermore, subsidence over the Alpine foreland, as a result of Alpine Pumping (Lugauer and Winkler, 2005), suppressed the CBL growth even more. The combination of both processes led to a height of the CBL well below the summit of the Hohenpeissenberg mountain at the time of the $\mathrm{O}_{3}$ drop event. Immersion of the mountain summit into the developing CBL can thus be definitely excluded as explanation.

4.6 Convective injection of surface layer air into levels above the ABL

The highly unstable conditions within the surface layer in the morning hours of 5 September 2005 suggested additional consideration of convective processes as a reason for the development of the $\mathrm{O}_{3}$ poor layer within the ABL. With a positive sensible heat flux (see Fig. 8a), a shallow but forced convection was established shortly after sunrise (06:00 h), initiating the development of a CBL. Increasing sensible heat flux and a simultaneously occurring secondary minimum of $u_{*}$ led to a dominance of buoyancy created turbulence over shear created turbulence (see Eq. 1), - a state of free convection. Somewhere, upwind of the mountain, a warm air mass, already heated up for several hours, became sufficiently buoyant and rose in a pulse-like motion up to its equilibrium height. As the air close to the ground was still poor of $\mathrm{O}_{3}$ but enriched in $\mathrm{CO}_{2}, \mathrm{H}_{2} \mathrm{O}$ and $\mathrm{NO}$, a small layer with lower $\mathrm{O}_{3}$ and higher $\mathrm{CO}_{2}, \mathrm{H}_{2} \mathrm{O}$ and $\mathrm{NO}$ values (compared to the 


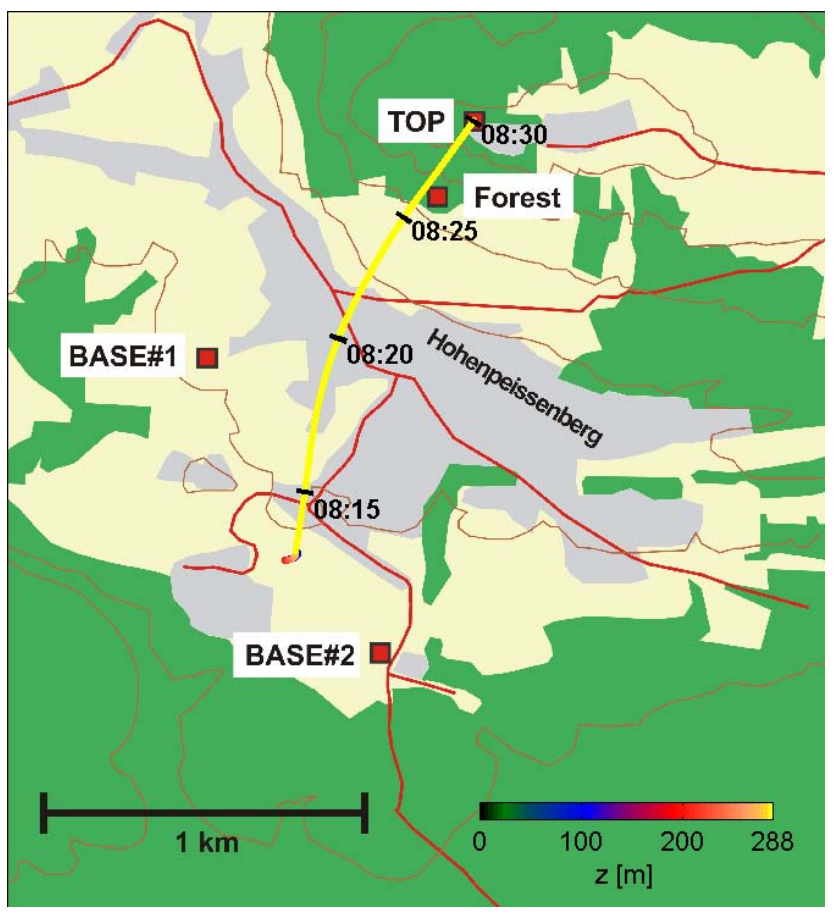

Fig. 10. Map of the village Hohenpeissenberg and the horizontal projection of a backward trajectory, computed for an impact at TOP station at 5 September 2005 08:30 h. The computed height a.g.l. of the air parcel is indicated by the colour of the trajectory. The convective ascent speed of the air mass was presumed to be in the order of $1.5 \mathrm{~m} \mathrm{~s}^{-1}$ from 0 to $288 \mathrm{~m}$ a.g.l. (with respect to BASE\#2). The wind field was based on SODAR measurements with the assumption of horizontal homogeneity. Note: the ascent needed only $3.2 \mathrm{~min}$ and is thus barely visible in the figure.

surrounding air) developed. Together with the surrounding air mass (which was still statically stable), it was horizontally advected towards the mountain. Recalling Fig. 5b, the wind speed at mountain summit remained at very low values for some hours. This explains, why the event duration at 5 September was quite long with a very slow recovery of the $\mathrm{O}_{3}$ values afterwards.

Two independent confirmations for such a process can be found in the dataset.

(1) The drop of air temperature (Fig. 8b), (not shown: simultaneous drop of $\mathrm{H}_{2} \mathrm{O}$ and $\mathrm{O}_{3}$ and increase of $\mathrm{CO}_{2}$ ) at the BASE shortly before the onset of the $\mathrm{O}_{3}$ decrease at the TOP station (see Fig. 4e). Again, the temporal concurrency of these observations with the TOP station observations suggests a common process. The air mass, being lifted by free convection in the surrounding of the BASE, had to be replaced by another air mass. This replacement air originated most probably from the trunk space of the nearby forest (see Fig. 10), encompassing the BASE from east to southwest.
Despite strong irradiance, the air in the trunk space was still relatively cold (air temperature drop), less affected by photochemistry than the air in the open surrounding of the BASE, and due to little vertical transport through the forest canopy still enriched in $\mathrm{CO}_{2}$, a remainder from the night time respiration of soil and plants. Other possible reasons for the temperature drop, like burning off of fog or mist can be excluded. Although earlier in the morning, the relative humidity ranged close to $100 \%$, it dropped down from saturation at least half an hour before the onset of the event. Patches of fog can be excluded by comparing the radiation temperature, derived from downwelling longwave radiation, with the air temperature. In case of fog, both temperatures should be very close, as fog temperature and air temperature would be the same (the location where radiative energy transfer occurs would be the upper surface of the fog layer). For 5 September, we observed a downwelling longwave radiation temperature being about $20 \mathrm{~K}$ lower than the air temperature. This indicates clear skies. Furthermore, no fog was observed at BASE during the morning hours of 5 September.

(2) A simple backward trajectory estimate confirmed that the source region of the convectively lifted air mass should have been at the southern part of the village Hohenpeissenberg, approx. $500 \mathrm{~m}$ northwest of the BASE (Fig. 10). For this estimate, some assumptions had to be made. First, the wind field was assumed to be horizontally homogeneous in all heights. This is a rough estimation, especially at low wind speeds, but for our purpose this approximation can be justified. With that, the wind vector at every time of the calculation was taken from the respective height of the SODAR wind profiles. Second, the convective vertical transport was assumed to be constant at approx. $1.5 \mathrm{~m} \mathrm{~s}^{-1}$ during the ascent from the surface to $288 \mathrm{~m}$ a.g.l. This is in accordance with textbook values for the convective velocity scale around 09:00 $\mathrm{h}$ in the morning (Stull, 1988). A direct calculation of the convective velocity scale from available data seemed to be inappropriate, as the described process must have been considerably stronger than the convective velocity within the still relatively shallow CBL.

According to (1) and (2), the phenomenon of $\mathrm{O}_{3}$ drop events at the mountain summit is thus a combination of a free convective pulse in the morning and a subsequent advection process transporting this air parcel towards the TOP station. The trigger of the free convective pulse can either be the wind speed minimum or just a sufficient energy input by solar radiation under low wind conditions. Whether the wind speed drops due to the onset of Alpine Pumping or is just ceasing due to the synoptical situation will not affect the development of an unstable condition and thus the release of a convective pulse. Furthermore, the observation of a wind speed minimum leading to a free convective pulse is subject to some luck, as convective cells are known to 
have a very limited horizontal dimension (Shen and Leclerc, 1997). On 5 September 2005 we had measured by chance within or close by such a cell. Nevertheless, convective cells can certainly develop without us being able to observe them in our ground based measurements. This explains, why some of the events listed in Table 2 are apparently not associated with a distinct wind speed minimum. The discrimination of $\mathrm{O}_{3}$ drop events at TOP site, as a result of a pulse of free convection, from other causes is thus the main challenge of evaluating a long time series of $\mathrm{O}_{3}$ measurements at the TOP station for the occurrence of $\mathrm{O}_{3}$ drop events with a similar causation as the events described in this paper.

\subsection{Long dataset}

Starting with one day (5 September 2005), where all observations were made just at the right place and time, and expanding the findings to a more than 5 years period, requires a critical limitation of possible statements. One of these limitations is a clear assignment of observed events to certain processes. The diurnal distribution of $\mathrm{O}_{3}$ drop event frequencies (Fig. 9) shows a clear difference between days with high global radiation and low global radiation. In the latter case, $\mathrm{O}_{3}$ drop events were distributed as a diurnal cycle over day times, with a weak maximum between 09:00 $\mathrm{h}$ and 10:00 $\mathrm{h}$ (Fig. 9, black bars). In contrast, for days with high global radiation, $\mathrm{O}_{3}$ drop event frequencies sharply peaked between 07:00 h and 09:00 h (Fig. 9, grey bars) and events were restricted to the morning hours. This gives evidence of a process, being restricted to high energy input and being primarily present in the early morning hours. However, it is possible that more than one of such processes exist, which can lead to the same phenomenon in the $\mathrm{O}_{3}$ time series. As described in Sect. 4.1, the independent phenomenon of Alpine Pumping is also bound to high global radiation days. It is able to provide a (secondary) wind speed minimum in the morning hours. From that we can make two statements: (a) due to Alpine Pumping, conditions favourable for free convection occur frequently in early morning hours of fair weather days, and (b) on fair weather days we observed the maximum frequency of $\mathrm{O}_{3}$ drop events at the TOP station. Together, this clearly points towards a convective pulse, as it was discussed in the previous section. Almost half of the events with high energy input (84 events) occurred at days when the mesoscale circulation Alpine Pumping occurred. We found Alpine Pumping to occur at $46 \%$ of all days during which total global radiation exceeded $20 \mathrm{MJ} \mathrm{m}^{-2}$. This is in excellent agreement with Lugauer and Winkler (2005), who found $42 \%$. The onset of the circulation, with its associated change of wind direction, must cause a short minimum of horizontal wind speed. Again, this points to a convective process, as low wind speeds are known to increase already present thermal instability. The other half of the events with high energy input (85 events) was not connected to Alpine Pumping. At least, characteristics of Alpine Pumping were not observable at the TOP station at these days. But horizontal wind speed is generally not very high during fair weather days, and can furthermore drop to low values for various reasons - leading to the same destabilisation of moist and heated air masses.

Daily total global radiation of more than $20 \mathrm{MJ} \mathrm{m}^{-2}$ at midlatitudes is restricted to a period approximately from April to September. During this period, the TOP site was in $18 \%$ of the days affected by an $\mathrm{O}_{3}$ drop event, coupled to high energy input, being most probably the result of a convective pulse. Half of those events are even more likely to originate from a free convective pulse, as they occurred at days with Alpine Pumping, where a short wind speed drop in the morning hours occurs. Furthermore, these numbers have to be taken as a minimum estimation, as the convectively lifted air masses do not necessarily have to be advected towards the TOP site, and they do not have to be trapped at just the right altitude to be intercepted by the TOP station.

Evidence for such free convection phenomena were recently found also for other locations (Eigenmann et al., 2008), although it was often not identified as active free convection (e.g. Hiller et al., 2008).

\section{Conclusions}

The observed $\mathrm{O}_{3}$ drop events result from free convection in the morning hours with the strength to rise far above the height of the growing CBL. The trigger of the convection can be manifold and are not necessarily limited to a mesoscale circulation system as it was the case in half of the days in this study. The described processes provide a powerful vertical transport mechanism in the early morning hours, which has a strong impact on atmospheric chemistry (trace gases) and meteorology (air temperature) close to ground as well as in higher altitudes.

The $\mathrm{O}_{3}$ drop events were not only observed during the field experiment but were present throughout the entire period from October 2000 to December 2005. On 18\% of the days between April and September, the $\mathrm{O}_{3}$ decreases are most likely the result of a free convective pulse in the early morning.

It can be expected that similar processes are active in many other regions, where appropriate triggers like local or mesoscale circulation systems lead to a convective release of surface layer air masses into the residual layer. Whether or not such transport events are sufficiently captured by common flux measurement techniques should be carefully investigated. This becomes particular true, when observed trace gas concentrations are to be assigned to possible source regions, only based on the wind direction.

Acknowledgements. The authors are grateful to all people supporting the field measurements, especially the staff of the Bauhof Hohenpeissenberg and families Schindler, Graf and Wiedemann. Special thanks belong to the German Meteorological Service and the staff of its observatory Hohenpeissenberg for performing 
additional measurements and providing data. The project was funded by Max Planck Society and German Science Foundation (DFG).

Edited by: A. Pszenny

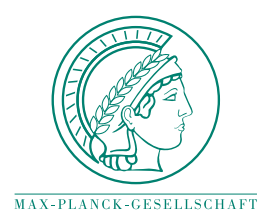

The publication of this article is financed by the Max Planck Society.

\section{References}

Aneja, V. P., Arya, S. P., Li, Y., Murray Jr., G. C., and Manuszak, T. L.: Climatology of Diurnal Trends and Vertical Distribution of Ozone in the Atmospheric Boundary Layer in Urban North Carolina, JAPCA J. Air Waste Ma., 50, 54-64, 2000.

Attmannspacher, W. and Hartmannsgruber, R.: On Extremely High Values of Ozone Near the Ground, Pure Appl. Geophys., 106108, 1091-1096, 1973.

Beyrich, F., Weisensee, U., Sprung, D., and Güsten, H.: Comparative analysis of sodar and ozone profile measurements in a complex structured boundary layer and implications for mixing height estimation, Bound. Lay. Meteorol., 81, 1-9, 1996.

Beyrich, F.: Mixing Height Estimation from SODAR Data - a Critical Discussion, Atmos. Environ., 31, 3941-3953, 1997.

Cheng, W.-L.: A vertical profile of Ozone concentration in the atmospheric boundary layer over central Taiwan, Meteorol. Atmos. Phys., 75, 251-258, 2000.

Corsmeier, U., Kalthoff, N., Kolle, O., Kotzian, M., and Fiedler, F.: Ozone concentration jump in the stable nocturnal boundary layer during a LLJ-event, Atmos. Environ., 31, 1977-1989, 1997.

Eigenmann, R., Metzger, S., Siebicke, L., Staudt, K., Serafimovich, A., and Foken, T.: Generation of free convection in a valley due to changes of the local circulation system, 18th Symposium on Boundary Layers and Turbulence, Am. Meteorol. Soc., Stockholm, 9-13 June 2008.

Fast, J. D., Doran, J. C., Shaw, W. J., Coulter, R. L., and Martin, T. J.: The evolution of the boundary layer and its effect on air chemistry in the Phoenix area, J. Geophys. Res.-Atmos., 105, 22 833-22 848, 2000.

Foken, T., Göckede, M., Mauder, M., Mahrt, L., Amiro, B. D., and Munger, J. W.: Post-field data quality control, in: Handbook of Micrometeorology: A Guide for Surface Flux Measurements, edited by: Kluwer, X. L. Dordrecht, 81-108, 2004.

Güsten, H., Heinrich, G., and Sprung, D.: Nocturnal depletion of ozone in the Upper Rhine Valley, Atmos. Environ., 32, 11951202, 1998.

Hastie, D. R., Narayan, J., Schiller, C., Niki, H., Shepson, P. B., Sills, D. M. L., Taylor, P. A., Moroz, W. J., Drummond, J. W., Reid, N., Taylor, R., Roussel, P. B., and Melo, O. T.: Observational evidence for the impact of the lake breeze circulation on ozone concentrations in Southern Ontario, Atmos. Environ., 33, 323-335, 1999.

Hiller, R., Zeeman, M. J., and Eugster, W.: Eddy-covariance flux measurements in the complex terrain of an Alpine valley in Switzerland, Bound.-Lay. Meteorol., 127, 449-467, 2008.
Holzworth, C. G.: Estimates of Mean Maximum Mixing Depths in the Contiguous United States, Mon. Weather Rev., 92, 235-242, 1964.

Holzworth, C. G.: Mixing depths, wind speeds, and air pollution potential for selected locations in the United States, J. Appl. Meteorol., 6, 1039-1044, 1967.

Lee, S.-M., Fernando, H. J. S., Princevac, M., Zajic, D., Sinesi, M., McCulley, J. L., and Anderson, J.: Transport and Diffusion of Ozone in the Nocturnal and Morning Planetary Boundary Layer of the Phoenix Valley, Environmental Fluid Mechanics, V3, 331362, 2003.

Lin, C.-H., Wu, Y.-L., Lai, C.-H., Lin, P.-H., Lai, H.-C., and Lin, P.L.: Experimental investigation of ozone accumulation overnight during a wintertime ozone episode in south Taiwan, Atmos. Environ., 38, 4267-4278, 2004.

Lugauer, M. and Winkler, P.: Thermal circulation in South Bavaria - climatology and synoptic aspects, Meteorologische Zeitschrift, 14, 15-30, 2005.

McKendry, I. G., Steyn, D. G., Lundgren, J., Hoff, R. M., Strapp, W., Anlauf, K., Froude, F., Martin, J. B., Banta, R. M., and Olivier, L. D.: Elevated ozone layers and vertical down-mixing over the Lower Fraser Valley, BC, Atmos. Environ., 31, 21352146, 1997.

McKendry, I. G., Steyn, D. G., O’Kane, S., Zawar-Reza, P., and Heuff, D.: Lower Tropospheric Ozone Measurements by Light Aircraft Equipped with Chemiluminescent Sonde, J. Atmos. Ocean. Techn., 15, 136-143, 1998.

Müller, H. and Sladkovic, R.: Case Studies of Frontal Passages in a Mountain Valley with Direct Access to the Bavarian Pre-Alpine Region Results from the German Front Experiment 1987, Meteorol. Atmos. Phys., 43, 77-87, 1990.

Prévôt, A. S. H., Dommen, J., Bäumle, M., and Furger, M.: Diurnal variations of volatile organic compounds and local circulation systems in an Alpine valley, Atmos. Environ., 34, 1413-1423, 2000.

Reitebuch, O., Strassburger, A., Emeis, S., and Kuttler, W.: Nocturnal secondary ozone concentration maxima analysed by sodar observations and surface measurements, Atmos. Environ., 34, 4315-4329, 2000.

Rummel, U.: Turbulent exchange of ozone and nitrogen oxides between an Amazonian rain forest and the atmosphere, University of Bayreuth, Bayreuth, 246 pp., 2005.

Salmond, J. A. and McKendry, I. G.: Secondary ozone maxima in a very stable nocturnal boundary layer: observations from the Lower Fraser Valley, BC, Atmos. Environ., 36, 5771-5782, 2002.

Seibert, P., Beyrich, F., Gryning, S. E., Joffre, S., Rasmussen, A., and Tercier, P.: Mixing layer depth determination for dispersion modeling, in: COST Action 710-Final Report. Harmonisation of the pre-processing of meteorological data for atmospheric dispersion models, edited by: Fisher, B. E. A., Erbrink, J. J., Finardi, S., Jeannet, P., and Thomson, D. J., European Commission, L-2985 Luxembourg, 145-265, 1998.

Shen, S. and Leclerc, M. Y.: Modelling the turbulence structure in the canopy layer, Physical and Biophysical Processes in the Vegetation Environment, 87, 3-25, 1997.

Strong, C., Fuentes, J. D., Davies, R. E., and Bottenheim, J. W.: Thermodynamic attributes of Arctic boundary layer ozone depletion, Atmos. Environ., 36, 2641-2652, 2002. 
Stull, R. B.: An introduction to boundary layer meteorology, Kluwer Academic Puplisher, Dordrecht, The Netherlands, 666 pp., 1988.

Talbot, R., Mao, H., Troop, D., Moore, B., Johnson, R., and Businger, S.: Smart balloon observations over the North Atlantic: Part I - Mini-O3 sampling of urban plumes, J. Geophys. Res., in press, 2006.
Vickers, D. and Mahrt, L.: Quality Control and Flux Sampling Problems for Tower and Aircraft Data, J. Atmos. Ocean. Techn., 14, 512-526, 1997.

Wanner, H., Künzle, T., Neu, U., Ihly, B., Baumbach, G., and Steisslinger, B.: On the Dynamics of Photochemical Smog over the Swiss Middleland - Results of the First POLLUMET Field Experiment, Meteorol. Atmos. Phys., 51, 117-138, 1993. 
Whiteman, C. D. and Bian, X.: Use of Radar profiler data to investigate large-scale thermally driven flows into the Rocky Mountains., 4th Int. Symp. trop. Profiling, Snowmass, Colorado, USA, 329-331, 1998.

Whiteman, C. D.: Mountain Meteorology, Oxford University Press, 355 pp., 2000.

Yelansky, N. F. and Senik, I. A.: Measurements of surface ozone concentrations at the high-mountain scientific station Kislovodsk: The seasonal and daily variations, Atmos. Ocean. Phys., 31, 235-243, 1995. 